\title{
Implementation of Smoke free policies in psychiatric inpatient care: A mixed methods study of practices and views and of psychiatrists' in an Australian mental health service
}

\author{
Sue Patterson ${ }^{1,2,3}$, Wilsen Drew ${ }^{1}$, Kirryn Chamberlain ${ }^{1}$ and Brett Emmerson ${ }^{1,4}$ \\ ${ }^{1}$ Metro North Mental Health, Metro North Hospital and Health Service, Australia \\ ${ }^{2}$ Department of Applied Psychology, Griffith University, Australia \\ ${ }^{3}$ School of Dentistry, The University of Queensland, Australia \\ ${ }^{4}$ School of Medicine, The University of Queensland, Australia
}

\begin{abstract}
Objective: to describe psychiatrists' views regarding implementation of smoke free policies in inpatient units, the acceptability and perceived helpfulness of a clinical pathway, and the frequency of provision and acceptability of various interventions.

Method: Sequential mixed-methods combining a questionnaire based survey with interviews with 43 psychiatrists working in two services in Queensland, Australia. Data were analysed descriptively and thematically.

Results: Psychiatrists agree that they have responsibility to assess smoking, encourage quitting and optimise management of nicotine withdrawal during admissions. Uncertainty remains about the rationale for 'smoke free', however. Psychiatrists express concern about 'rights' of patients and others, paternalistic restriction of choice and their roles as agents of government, rather than health professionals. Most psychiatrists assess smoking informally, with intervention titrated to perceived motivation to quit. The manner in which conversations are approached and interventions are offered is critical to engagement of patients.

Conclusions: Psychiatrists are overcoming longstanding ambivalence and therapeutic nihilism that have hindered integration of management of smoking in clinical care. Sustained improvement will depend on frank engagement with lingering concerns, careful management of the 'unintended' consequences of smoke-free policies and ensuring that clinicians are resources appropriately.
\end{abstract}

\section{What is known about the topic?}

Addressing tobacco smoking among people living with severe mental illness is an economic and ethical imperative. While psychiatrists are obliged to assess and intervene to reduce smoking and legislation requires health services to be smoke-free, smoking in psychiatric inpatient units has remained contentious and problematic internationally. Partial adherence to regulations and inconsistent provision of interventions have been linked to ambivalent cultures, organisational factors including 'lack of time' and clinician beliefs and capabilities. Because success of reinvigorated efforts to implement smoke-free policies depends on actions of clinicians understanding views and motivations that enable or inhibit action, is critical to design of strategies to optimise practice.

\section{What does this paper add?}

Insight to the complex reasoning of psychiatrists in relation to assessment of tobacco smoking and deployment of interventions. Psychiatrists endorse smoke-free in principle and acknowledge potential benefit but concern about inhibition of rights and capacity of patients to engage contribute to ambivalence and variability in practice.

\section{What are the implications for practitioners?}

Opportunities to engage, with other clinicians in critical discussion of the principles and application of smoke free policies is critical to increased 'buy in' and clarity of purpose.

Tobacco smoking is the leading cause of the cardiovascular and respiratory diseases which substantially curtail life expectancy of people with severe mental illness(SMI) [1,2]. With disproportionately high rates of smoking, increased nicotine dependence and inconsistent engagement in preventative healthcare, people with SMI have been identified as deserving targeted intervention $[3,4]$. Hence, and because smoking impacts metabolism of psychotropic medications and mood, psychiatrists are obliged to assess and intervene to reduce smoking [5-9]. However, and despite legislation obliging health services to

Correspondence to: Sue Patterson, J Floor Mental Health Centre, Royal Brisbane and Women's Hospital, Herston Queensland 4029. Australia; E-mail: Susan. Patterson@health.qld.gov.au

Key words: smoking, intervention, inpatient, psychiatry, mixed-methods

Received: November 20, 2017; Accepted: December 22, 2017; Published: December 27, 2017 
Patterson S (2017) Implementation of Smoke free policies in psychiatric inpatient care: A mixed methods study of practices and views and of psychiatrists' in an Australian mental health service

be smoke-free, smoking in psychiatric inpatient units has remained contentious and problematic internationally [8-11]. Partial adherence to regulations and inconsistent provision of interventions have been linked to ambivalent cultures within which smoking is considered 'not worth making a fuss over', clinicians' use of cigarettes to manage behaviour and (erroneous) beliefs that patients are neither motivated nor capable of quitting [10-14]. Clinicians, including psychiatrists have identified lack of time, training and confidence as barriers to addressing smoking in their patients [12-15].

Increasing evidence that patients can quit, strengthening of legislation and increased attention to physical health of people with SMI have reinvigorated efforts to integrate management of smoking in inpatient care. Because success depends, fundamentally on actions of clinicians, 10,13 understanding views and motivations that enable or inhibit action, is critical to design of strategies to optimise practice.

\section{Method and Setting}

We used sequential mixed methods, to describe the views and practices of consultants, senior medical officers, and registrars (hereafter psychiatrists) working in acute adult inpatient settings in one of the largest mental health services (MHS) in Australia. The service provides community based services to a population approaching $1,000,000$ with inpatient care provided at three hospitals. Participants were recruited from two of these settings. $s$

The service (re)enacted a smoke-free policy [16], as summarised in box 1, in April 2016. Implementation was supported by protocols, formal and 'ad-hoc 1:1' education (encompassing impact of smoking, completion of SCCP, NRT and evidence that patients can quit), by dualdiagnosis clinicians and pharmacists, and provision of pre-populated NRT prescription forms. Responsibility for completion of the SCCP was shared by ward staff at RS and allocated to psychiatrists at ICS.

Designed to support quality improvement, the study was granted exemption from review by the Chairperson of a certified Human Research Ethics Committee(HREC16/QRBW/124).

\section{Data Collection and analysis}

Data collected in a questionnaire-based survey and interviews examined the acceptability and perceived helpfulness of the SCCP, and the frequency of provision and acceptability of various interventions.

The questionnaire (available on request), designed to address objectives was distributed, with information sheet attached, to psychiatrists attending three routine education meetings in July 2016 (three months post policy implementation). Psychiatrists were invited to complete the questionnaire anonymously, with return implying consent to use of data. Data were entered to SPSS v21 for analysis. When comparison of responses using X2 by gender and professional status demonstrated no significant differences within the sample, data were collectively summarised using descriptive statistics. Results were presented to, and explored in group and individual interviews with a convenience sample $(\mathrm{N}=18)$ psychiatrists from the services. These psychiatrists were invited to share views about the smoke-free policy, reported practice and impact on patient care. Participants provided consent to audio recording, transcription and analysis of discussions for study purposes. Analysis employed the framework approach [17].

\section{Results}

Nearly all (43/45;96\%) distributed questionnaires were returned. Respondents, including 23 consultants, were aged 22-68 (M40) years. Most respondents $(n=27)$ and consultants $(n=17)$ were male. Experience in mental health ranged from $<12$ months to 42 years, (M13.5), with women significantly less experienced than men (M7.5 vs M17.2years) ( $t(40)-2.739, p$.03). The vast majority ( $n=39 ; 90 \%)$ were 'non-smokers' with four having quit $>$ six months previously. Two of the four smokers (including two consultants) reported wanting to quit. Majorities, collectively $(\mathrm{n}=30 ; 70 \%)$, and at each site reported 'being trained' in SCCP.

Analysis demonstrated consensus among respondents regarding the majority of questionnaire items related to the responsibilities of MHS and roles of psychiatrists (Table 1). All agreed/strongly agreed that MHS should ask about smoking and assist patients to quit; all but one that MHS should advise patients to quit and that encouraging quitting was part of their role. Around one quarter however, agreed with statements that admission to hospital was the worst time to encourage quitting, and the wrong time to quit. Opinion was divided in relation to confiscation of cigarettes and analysis demonstrated ambivalence around the utility of SCCP, with around a third reporting being 'unsure' whether use would help patients quit and one in seven disagreeing with the statement 'the pathway is useful in management of smoking'. Most respondents reported offering at least minimal intervention -advice and NRT patches and gum (Table 2). Referral to Quit line and GPs were also offered by the majority, but less frequently. While most respondents perceived patients as 'somewhat receptive' or ambivalent in relation to most interventions, some respondents consistently reported that patients were somewhat unreceptive.

Table 1. Psychiatrists' views about assessment and management of smoking in inpatient units

\begin{tabular}{|c|c|c|c|c|}
\hline \multirow[t]{2}{*}{$\begin{array}{l}\text { Please indicate your level of agreement with } \\
\text { the following statements }\end{array}$} & 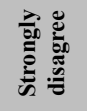 & 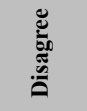 & 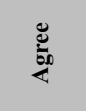 & 至 \\
\hline & $\mathrm{n}(\%)$ & n $(\%)$ & n $(\%)$ & $\mathrm{n}(\%)$ \\
\hline $\begin{array}{l}\text { MH services should ask inpatients about } \\
\text { smoking }\end{array}$ & 0 & 0 & $14(33)$ & $28(67)$ \\
\hline $\begin{array}{l}\text { MH services should advise inpatients to quit } \\
\text { smoking }\end{array}$ & 0 & $1(2)$ & $19(44)$ & $22(52)$ \\
\hline $\begin{array}{l}\text { MH services should assist inpatients to quit } \\
\text { smoking }\end{array}$ & 0 & 0 & $17(40)$ & $25(58)$ \\
\hline $\begin{array}{l}\text { MH services should confiscate cigarettes from } \\
\text { inpatients }\end{array}$ & $2(5)$ & $19(44)$ & $14(33)$ & $6(14)$ \\
\hline Patient's smoking is not our business & $14(33)$ & $24(56)$ & $3(7)$ & $1(2)$ \\
\hline $\begin{array}{l}\text { Effective management of nicotine withdrawal } \\
\text { is important to best outcomes in inpatient } \\
\text { units }\end{array}$ & 0 & 0 & $16(37)$ & $26(60)$ \\
\hline $\begin{array}{l}\text { Admission to inpatient units is the WRONG } \\
\text { time to quit }\end{array}$ & $7(16)$ & $25(58)$ & $9(20)$ & $1(2)$ \\
\hline $\begin{array}{l}\text { Admission to hospital is the WORST TIME } \\
\text { to encourage quitting }\end{array}$ & $6(14)$ & $27(63)$ & $6(14)$ & $3(7)$ \\
\hline $\begin{array}{l}\text { Management of smoking is NOT part of my } \\
\text { role }\end{array}$ & $15(35)$ & $26(60)$ & $1(2)$ & 0 \\
\hline $\begin{array}{l}\text { Asking patients about their smoking is part } \\
\text { of my role }\end{array}$ & 0 & 0 & $25(58)$ & $17(40)$ \\
\hline $\begin{array}{l}\text { I consider it my job to encourage patients to } \\
\text { quit smoking }\end{array}$ & 0 & $1(2)$ & $22(51)$ & $19(44)$ \\
\hline $\begin{array}{l}\text { I consider it part of my role to help patients to } \\
\text { quit smoking }\end{array}$ & 0 & $1(2)$ & $25(51)$ & $16(37)$ \\
\hline Patients are not interested in quitting & $4(9)$ & $18(42)$ & $4(9)$ & 0 \\
\hline $\begin{array}{l}\text { I am confident providing advice about } \\
\text { smoking and quitting }\end{array}$ & 0 & $3(7)$ & $27(63)$ & $13(30)$ \\
\hline I am confident offering inpatients NRT & 0 & $5(12)$ & $24(56)$ & $13(30)$ \\
\hline $\begin{array}{l}\text { Overall, The Pathway is useful in } \\
\text { management of smoking }\end{array}$ & 0 & $6(14)$ & $23(53)$ & $12(28)$ \\
\hline
\end{tabular}


Patterson S (2017) Implementation of Smoke free policies in psychiatric inpatient care: A mixed methods study of practices and views and of psychiatrists' in an Australian mental health service

Analysis of qualitative data demonstrated the complexity of psychiatrists' thinking about smoking in inpatient settings. The rationale for smoke-free environments and related processes was a central issue (Table 3).

What's the principle? Is it because even though people have the right to smoke they don't have the right to impose tobacco on others...are we protecting smoker's health, or protecting others, or saying that the government says that smoking is, like heroin, illegal, so we're imposing the law(Consultant)

Concern was expressed that prohibition was 'paternalistic', a further infringement of already curtailed rights, particularly for patients admitted involuntarily, and about psychiatrists acting as 'authoritarian' instruments of government. Some questioned the fit of restriction of choice (to smoke), with self-determination endorsed in 'recovery agenda' and noted that prohibition was sometimes experienced as disempowering by patients. The proposal by one that patients who articulated a reasoned choice to continue smoking ought to be enabled to do so, however was not widely supported. Psychiatrists spoke of the potential for (mis)application of the Mental Health Act to prevent absconding (to smoke) by patients whose treatment would otherwise be voluntary, and refusal of voluntary admission when clinically indicated, by patients who smoked. Aggression as a consequence of the ban was canvassed with one psychiatrist reporting 'being told' of incidents. However as another noted, causes of aggression were commonly complex and may be attributed to the manner in which practice was enacted. While recognising prohibition as 'a double edged sword' consensus was it upheld rights of 'others' (patients, visitors, staff) to safe environments, and was 'good for' patients. Indeed nonengagement of psychiatrists with smoking was described as failing to fulfil obligations and perpetuating disadvantage and premature death. A registrar encapsulated the collective opinion observing:

\section{Ultimately it provides more benefit than problems.}

Opinions diverged, however about confiscation of tobacco. Whereas some justified the practice as a means to creating the

Table 2. Frequency with which interventions are offered

\begin{tabular}{|c|c|c|c|c|}
\hline intervention & $\begin{array}{c}\text { Never } \\
\text { (no patients) } \\
\text { n (\%) }\end{array}$ & $\begin{array}{c}\text { Occasionally } \\
\text { (few } \\
\text { patients) } \\
\text { n (\%) }\end{array}$ & $\begin{array}{c}\text { Usually } \\
\text { (most } \\
\text { patients) } \\
\mathbf{n}(\mathbf{\%})\end{array}$ & $\begin{array}{c}\text { Always } \\
\text { (all patients) } \\
\text { n (\%) }\end{array}$ \\
\hline Advice about quitting & 0 & $8(19)$ & $19(44)$ & $15(23)$ \\
\hline Nicotine replacement patches & $3(7)$ & $5(12)$ & $17(40)$ & $17(40)$ \\
\hline Nicotine replacement gum & $2(5)$ & $8(19)$ & $17(40)$ & $15(35)$ \\
\hline Referral to Quitline & $7(16)$ & $9(20)$ & $20(47)$ & $6(14)$ \\
\hline Referral to GP & $6(14)$ & $12(28)$ & $18(42)$ & $6(14)$ \\
\hline
\end{tabular}

Table 3. Perceived receptivity of patients to interventions

\begin{tabular}{|c|c|c|c|c|c|}
\hline Intervention & $\begin{array}{c}\text { Very } \\
\text { receptive / } \\
\text { welcoming } \\
\text { n (\%) }\end{array}$ & $\begin{array}{c}\text { Somewhat } \\
\text { receptive } \\
\text { n (\%) }\end{array}$ & $\begin{array}{c}\text { Neither } \\
\text { receptive nor } \\
\text { hostile } \\
\text { n (\%) }\end{array}$ & $\begin{array}{c}\text { Somewhat } \\
\text { unreceptive } \\
\text { n (\%) }\end{array}$ & $\begin{array}{c}\text { Hostile / } \\
\text { actively } \\
\text { rejecting } \\
\text { n (\%) }\end{array}$ \\
\hline $\begin{array}{c}\text { Advice about } \\
\text { quitting }\end{array}$ & $1(2)$ & $32(74)$ & $4(9)$ & $4(9)$ & $1(2)$ \\
\hline $\begin{array}{c}\text { Nicotine } \\
\text { replacement } \\
\text { patches }\end{array}$ & $3(7)$ & $23(53)$ & $10(23)$ & $6(14)$ & 0 \\
\hline $\begin{array}{c}\text { Nicotine } \\
\text { replacement } \\
\text { gums }\end{array}$ & $4(9)$ & $20(47)$ & $11(26)$ & $7(16)$ & 0 \\
\hline $\begin{array}{c}\text { Referral to } \\
\text { Quitline }\end{array}$ & 0 & $17(40)$ & $17(40)$ & $7(16)$ & $1(2)$ \\
\hline $\begin{array}{c}\text { Referral to } \\
\text { GP }\end{array}$ & $2(5)$ & $20(47)$ & $13(30)$ & $6(14)$ & $1(2)$ \\
\hline
\end{tabular}

desired environment, free of triggers, others challenged the practice as discriminatory, because cigarettes are not removed in non-mental health settings. Several unintended impacts of the practice, such as exacerbation of financial hardship when patients purchased then relinquished cigarettes on each occasion of leave; concealment of cigarettes on hospital grounds for use on leave; visitors 'supplying' cigarettes, were described.

Asked about observed variability in offering interventions and receptivity of patients, psychiatrists typically emphasised pressure of work and patient factors. They agreed that ideally patients would engage collaboratively in structured assessment and management of smoking and withdrawal but noted that at admission many were too unwell and/or agitated to participate and were thus regarded as unreceptive. The SCCP was regarded as a useful in providing a structure for conversations, but lacking time to undertake comprehensive motivational interviews, psychiatrists described informal assessment as usual practice. They reported gauging each patient's relationship with smoking and potential receptivity to intervention at a given time.

You pick up cues: If someone says 'I smoke 35 cigarettes, I know that's really bad you', I'll intervene, but if they're always asking 'when can I go out for my smoke?', you feel well, why bother? (Registrar)

Psychiatrists agreed that because patients typically linked admission with imposed 'quitting' and resented this, timing and personalising approach was critical to receptivity.

When patients are highly agitated, withdrawing from drugs, very psychotic, just leave them alone...pick up the conversation on the ward. (Consultant)

Being non-judgemental - not 'banging on about something else that's wrong with them' and clear that the purpose of NRT during the admission was reduction in withdrawal symptoms were regarded as critical to engaging patients in the conversation. Quitting was an 'ideal' but not short term outcome.

We're a bit confused about what we're saying. Quitting is not the real issue; it's 'We need to find a way to manage your not smoking while you're in here'. People have worried about that and are receptive...' What can you give me?' You've got a conversation.(Consultant)

Operating under total, rather than partial, smoking ban was considered helpful for two key reasons: (1) patients were treated consistently and equally reducing risk of 'playing staff off', (2) psychiatrists were able to shift locus of responsibility for the patient's discomfort, enabling therapeutic engagement.

You're able to make it clear that nothing they can say is going to enable them to have a cigarette: 'look it's out of my hands, there is this policy we have to abide by, to enforce (Registrar)

With many describing post-discharge 'adjustment of smoking' psychiatrists observed that positive experiences of smoking-related conversations and NRT during admission could prompt quit attempts, particularly when clinicians continued conversations in the community.

\section{Discussion}

Findings should be considered in light of limitations related to the descriptive, cross-sectional design and conduct of the study in particular settings in which a proactive approach has been taken to enacting smoke-free policies. Findings are a point in time 'snap-shot' of views and practice of a non-random sample of psychiatrists; while their accounts support understanding and interpretation, generalisability 
Patterson S (2017) Implementation of Smoke free policies in psychiatric inpatient care: A mixed methods study of practices and views and of psychiatrists' in an Australian mental health service

is uncertain. We have no reason to believe that participants differ systematically from peers working in other sites but it is likely that environmental characteristics, including policy implementation activities have shaped views. Nonetheless findings are, encouragingly consistent with emergent evidence that mental health services can successfully implement smoke free policies and have implications for implementation of smoke-free policies in other contexts.

Psychiatrists it seems are overcoming the ambivalence and therapeutic nihilism that has hindered integration of management of smoking in clinical care [10-13]. Conceding the devastating consequences of continued neglect of smoking on patients individually and collectively, psychiatrists acknowledged the profession's obligations to proactively engage in holistic care, and generally endorsed total bans as appropriate in inpatient units. This position was reinforced by personal experience of positive outcomes. Consistent with robust evidence, psychiatrists recognised that (some) patients are (or can be) motivated to quit and that sensitively delivered, personalised intervention in hospital, particularly management of nicotine withdrawal, is beneficial. Notwithstanding broad consensus that 'smoke free' is a good thing, robust discussion of the rationale for policy and various practices suggests lingering ambivalence. In the language of normalisation process theory, which provides a conceptual model for understanding implementation of new 'technologies, psychiatrists are cognitively engaged, undertaking collective action and reflexively appraising the consequences of their contributions [18]. Full integration such that the philosophy and practices are communally reproduced and sustained,18 however will require further sustained investment. Literature around implementation suggests three things as critically important: identifying and addressing concerns, careful management of the 'unintended' consequences and ensuring that clinicians are resources appropriately. Practically, clinicians need time to engage meaningfully with patients, particularly those who appear pre-contemplative and currently receive only NRT.

Fundamentally, given absence of consensus among staff has undermined implementation of smoke free policies $[9,10,13]$ it seems critical that opportunities be created for critical dialogue, for example of tensions around 'rights to smoke' and the 'soft paternalism' inherent in smoke-free policy. While recourse will always be available to 'it's the law' and this may be sufficient rationale for some, psychiatrists and others involved should be encouraged to air and examine concerns, to weigh up the evidence and arguments such that they are able to embed their practice in a coherent framework. This will enable the proactive and authentic engagement about physical health desired by patients [19].

\section{Acknowledgements}

This study was conducted with in-kind support of Metro North Mental Health and a grant to Metro North Mental Health, Redcliffe Caboolture by the School of Medicine, The University of Queensland. The authors are grateful to the psychiatrists who made time to complete the questionnaire and participate in interviews. The contributions of Anna Praskova to study and questionnaire design and
Trevor Hollingsworth and Vikas Moudgil in enabling participation of psychiatrists are gratefully acknowledged. The authors declare they have no conflicts of interest.

\section{References}

1. Osborn D, Levy G, Nazareth I, Petersen I, Islam A, et al. (2007) Relative risk of cardiovascular and cancer mortality in people with severe mental illness from the United Kingdom's General Practice Research Database. Arch Gen Psychiatry 64: 242249. [Crossref]

2. Brown S, Inskip H, Barraclough B (2000) Causes of the excess mortality of schizophrenia. Br J Psychiatry 177: 212-217. [Crossref]

3. Lasser K, Boyd JW, Woolhandler S, Himmelstein DU, McCormick D, et al. (2000) Smoking and mental illness: A population-based prevalence study. JAMA 284: 26062610. [Crossref]

4. Williams JM, Steinberg ML, Griffiths KG, Cooperman N (2013) Smokers With Behavioral Health Comorbidity Should Be Designated a Tobacco Use Disparity Group. Am J Public Health 103(9):1549-1555. [Crossref]

5. Rogers E, Sherman S (2014) Tobacco use screening and treatment by outpatient psychiatrists before and after release of the American Psychiatric Association treatment guidelines for nicotine dependence. Am J Public Health 104(1): 90-5. [Crossref]

6. Shiers D, Bradshaw T, Campion J (2015) Health inequalities and psychosis: time for action. Br J Psychiatry 207: 471-473. [Crossref]

7. American Psychiatric Association (1996) Practice guideline for the treatment of patients with nicotine dependence. Am J Psychiatry 153(10 Suppl): 1-31. [Crossref]

8. Mendelsohn CP, Kirby DP, Castle DJ (2015) Smoking and mental illness. An update for psychiatrists. Australas Psychiatry 23: 37-43. [Crossref]

9. Allan J (2013) Smoking: time for the mental health system to confront its own ambivalence. Australas Psychiatry 21(3): 203-205. [Crossref]

10. Lawn S, Campion J (2013) Achieving Smoke-Free Mental Health Services: Lesson from the Past Decade. International Journal Environmental Research and Public Health. Int J Environ Res Public Health 10(9): 4224-4244. [Crossref]

11. Burki TK (2014) Smoking and mental illness-time to break the link. Lancet Respir Med 2: 177. [Crossref]

12. Magor-Blatch LE, Rugendyke AR (2016) Going smoke-free: attitudes of mental health professionals to policy change. J Psychiatr Ment Health Nurs 23: 290-302. [Crossref]

13. Campion J, Lawn S, Brownlie A, Hunter E, Gynther B, et al. (2008) Implementing smoke-free policies in mental health inpatient units: Learning from unsuccessful experience. Australas Psychiatry 16: 92-97. [Crossref]

14. Sheals K, Tombor I, McNeill A, Shahab L (2016) A mixed-method systematic review and meta-analysis of mental health professionals' attitudes toward smoking and smoking cessation among people with mental illnesses. Addiction 111: 1536-1553. [Crossref]

15. Wye P, Bowman J, Wiggers J, Baker A, Knight J, et al. (2010) Total smoking bans in psychiatric inpatient services: a survey of perceived benefits, barriers and support among staff. BMC Public Health 10: 372. [Crossref]

16. Service policies (withheld for review)

17. Gale N, Heath G, Cameron E, Rashid S, Redwood S (2013) Using the framework method for the analysis of qualitative data in multi-disciplinary health research. BMC Med Res Methodol 13: 117. [Crossref]

18. May C, Finch T (2009) Implementation, embedding, and integration: an outline of Normalization Process Theory. Sociology 43: 535-554.

19. Young SJ, Praskova A, Hayward N, Patterson S (2016) Attending to physical health in mental health services in Australia: a qualitative study of service users' experiences and expectations. Health Soc Care Community 25(2): 602-611. [Crossref]

Copyright: (C2017 Patterson S. This is an open-access article distributed under the terms of the Creative Commons Attribution License, which permits unrestricted use, distribution, and reproduction in any medium, provided the original author and source are credited. 